Editor's Note: Toolboxes are a new, occasional feature in the Journal designed to briefly highlight a new method or a resource of general use in neuroscience or to critically analyze existing approaches or methods. For more information, see http://www. jneurosci.org/itoa.shtml.

\title{
Microtargeted Gene Silencing and Ectopic Expression in Live Embryos Using Biolistic Delivery with a Pneumatic Capillary Gun
}

\author{
Orit Shefi, ${ }^{1}$ Claire Simonnet, ${ }^{2}$ Michael W. Baker, ${ }^{1}$ James R. Glass, ${ }^{3}$ Eduardo R. Macagno, ${ }^{1}$ and Alex Groisman ${ }^{2}$ \\ ${ }^{1}$ Division of Biological Sciences, University of California, San Diego, La Jolla, California 92093-0376, ${ }^{2}$ Department of Physics, University of California, San \\ Diego, La Jolla, California 92093-0374, and ${ }^{3}$ Seashell Technology, La Jolla, California 92037
}

Key words: RNAi; ectopic expression; biolistic delivery; axon growth; Hirudo medicinalis; netrin; gene gun

\section{Introduction}

Modulating gene expression, either by transfection or by RNA interference (RNAi), is a powerful means for studying the functions of essential genes during nervous system development and maintenance. Both approaches depend on the successful delivery of the corresponding nucleic acids into the targeted cells. Current methods for introducing DNA and RNA into cells and tissues include viral transformation, lipofection, electroporation, direct injection through microcapillaries, and biolistics. In the last technique, the molecules to be delivered are carried by micron-size particles of a heavy metal that are accelerated to high speeds by flow of a gas and launched into the target tissue (Klein et al., 1987). The substances injected into cells using the biolistics technique have included DNA (Klein et al., 1987; Mehier-Humbert and Guy, 2005), fluorescent dyes (Gan et al., 2000), and, most recently, double-stranded RNA

Received March 22, 2006; revised April 21, 2006; accepted April 21, 2006. This work was supported by National Institutes of Health Grants 1 R41 MH076332-01 (C.S., J.R.G., and A.G.) and 1R01 NS043546 (0.S., M.W.B., and E.R.M.). We thank Sandra Peterson for technical assistance.

Correspondence should be addressed to either Orit Shefi or Alex Groisman, Division of Biological Sciences, University of California, San Diego, 9500 Gilman Drive, La Jolla, CA 92093-0376. E-mail: oshefi@ucsd.edu or agroisman@ucsd.edu.

DOI:10.1523/JNEUROSCI.1237-06.2006

Copyright $\odot$ 2006 Society for Neuroscience $\quad$ 0270-6474/06/266119-05\$15.00/0
(dsRNA) (Hon et al., 2004; Kim et al., 2005). Particle-mediated delivery is not sensitive to permeability of the cell membrane by specific reagents and lacks the potentially deleterious effects of viruses and lipofection. It is particularly advantageous for live tissue applications, because it does not rely on molecular diffusion within tissue and can target cells in internal layers. Nevertheless, the application area of the particle-mediated delivery has been limited by the current design of "gene guns" used for particle acceleration. These gene guns, including the table-top PDS-1000 and the popular hand-held Helios (both commercially available from Bio-Rad, Hercules, CA) that are powered by pulses of highly pressurized helium (He), deliver particles to large areas (square centimeters) with limited accuracy and reproducibility. In addition, the tissue targeted by a Helios gun may be damaged by the high-speed jet of $\mathrm{He}$ emerging from the gun nozzle.

Recently, a new type of pneumatic gun has been introduced (Rinberg et al., 2005) (Fig. 1A), in which particles are injected into a continuous stream of high-speed He in a capillary tube and accelerated up to speeds of $300-400 \mathrm{~m} / \mathrm{s}$. The stream of He emerging from the capillary outlet is completely diverted into a coaxial capillary of larger diameter, to which vacuum is applied, while the particles continue in their trajectories and retain their high speeds. The area targeted by this pneumatic capillary gun (called "the gun" in the rest of the text) is defined by the size of a nozzle, a circle $150 \mu \mathrm{m}$ in diameter, at the end of the outer capillary.

Here we describe the application of the capillary gun for fast, accurate, and highly localized biolistic delivery of dsRNA and plasmid DNA into muscle cells and central neurons in internal layers of live embryos of the leech, Hirudo medicinalis. The leech embryo is proving to be a useful model for studying the effects of changing expression levels of specific genes on morphology and function of the nervous system (Aisemberg et al., 1997; Baker and Macagno, 2000; Wang et al., 2005). We demonstrate silencing of expression of the axon guidance factor netrin by RNAi, as well as ectopic expression of actin tagged with a fluorescent protein, in small clusters of longitudinal muscle cells and central neurons. We also show the biolistic transfection and staining in monolayer cultures of mammalian cells. Finally, we carry out independent injection of two different lipophilic tracking dyes with a single capillary gun.

\section{Experimental setup}

To adapt the gun for accurate delivery of particles into the embryos, it was mounted on a micromanipulator, and a specially designed head was attached to 
the gun (Fig. $1 B$ and supplemental Fig. 1, available at www.jneurosci.org as supplemental material). The head was machined of Plexiglas, and its upper part contained a semiconductor laser with a lens, generating a beam of light directed through the inner capillary, focused at the embryo surface (a few millimeters from the nozzle) and used for aiming (Fig. $1 B$, inset). The surface of the embryo was imaged with a video microscope (magnification, $0.7 \times-$ $4.5 \times)$. The lower part of the head had a He outlet at the bottom, connected to the gun through a luer adapter, and three inlets on the sides that were all connected to a single source of pressurized He through separate lines of tygon tubing. One line was always open, creating continuous flow of He through the gun. Two other lines were normally closed by solenoid valves and contained gold carrier particles (1.6 $\mu \mathrm{m}$ in diameter) with different coatings that were loaded into the tubing as a dry powder. A shot was generated by opening one of the valves for $0.3 \mathrm{~s}$, causing the injection of a bolus of particles from the corresponding tubing line into the gun. One load of particles weighed $\sim 0.5$ mg and could typically be used for up to 10 shots, with a single shot usually delivering on the order of a few hundred particles. The tubing was gently tapped between the shots to dislodge particles and facilitate their injection into the $\mathrm{He}$ stream in the gun.

The outer capillary of the gun was connected to a vacuum system with a gauge pressure of -12.5 psi. The pressure of $\mathrm{He}$ was varied between 10 and 15 psi to adjust the particle penetration depth. The upper pressure limit was set by a level at which a jet of He started to emerge from the gun nozzle (Rinberg et al., 2005). Distributions of penetration depths of the particles into leech embryos (Fig. 1C) were similar to the distributions obtained previously with agarose gels (Rinberg et al., 2005). Importantly, at all He pressures tested, the distributions had a single peak, and the particles were localized in a narrow interval of depths around the peak (width at half height of $\sim 15 \mu \mathrm{m}$ ).

\section{RNAi of netrin}

We performed RNAi of netrin expression in ventral longitudinal muscle cells and central neurons of leech embryos using particles coated with netrin dsRNA (see supplemental material, available at www. jneurosci.org, for the animal preparation and particle coating protocols). In the embryonic stages we used [embryonic day 8 (E8) to E12], the longitudinal muscle cells
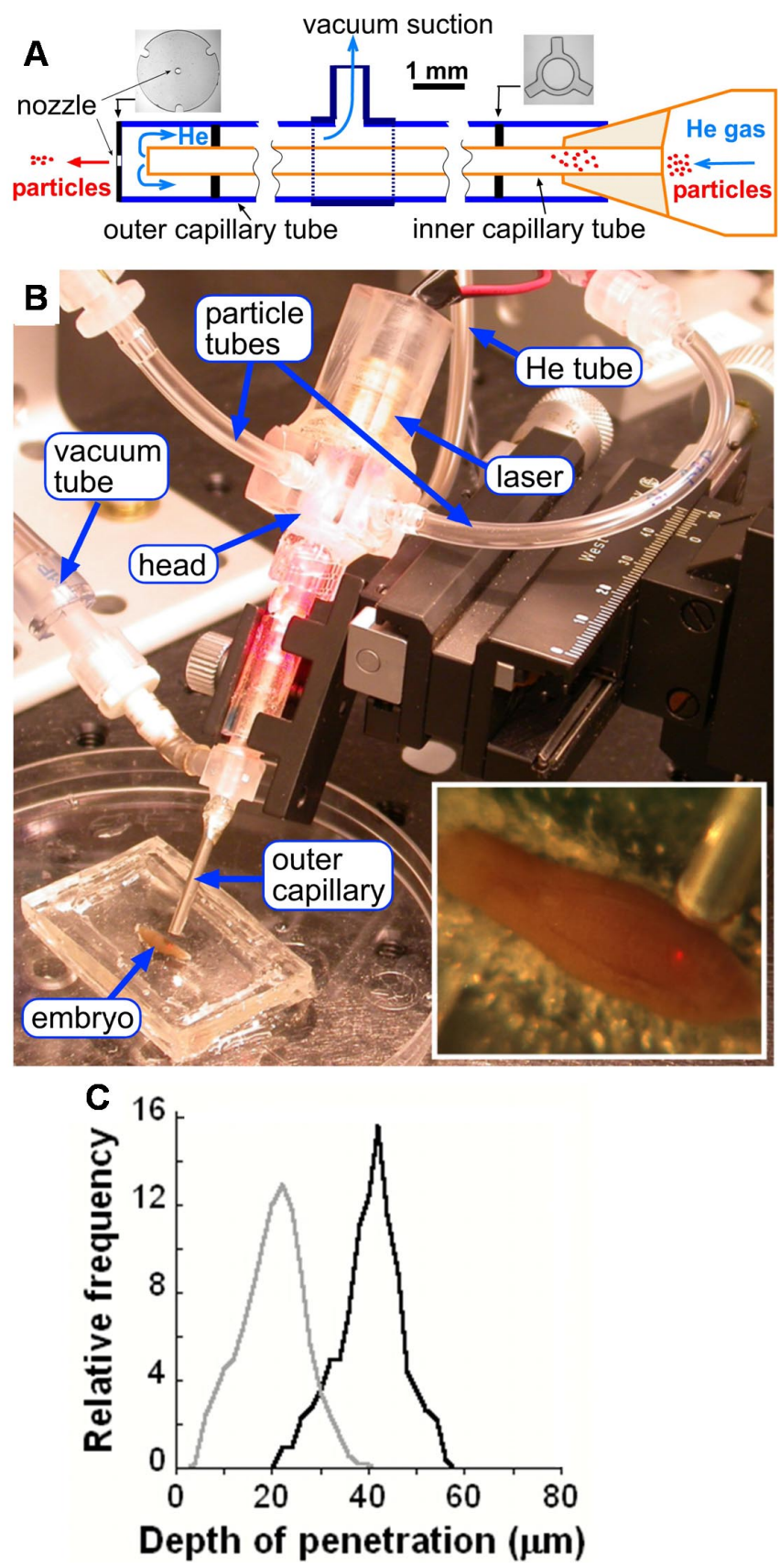

Figure 1. A, Schematic drawing of the cross section of the capillary gun. $\boldsymbol{B}$, Photograph of the gun with a head attached, mounted on a micromanipulator, and aimed at a leech embryo. Inset, Close-up view of the leech embryo with a laser spot (red dot); the end of the gun is seen extending from the top right corner. $C$, Distributions of penetration depths of $1.6 \mu \mathrm{m}$ gold particles in leech embryos. The particles were shot at He pressures and distances between the nozzle and the embryo of $14.5 \mathrm{psi}$ and $2 \mathrm{~mm}$, respectively (black curve), and of $10 \mathrm{psi}$ and $4 \mathrm{~mm}$, respectively, (gray curve). The distributions were obtained by fixing the tissue and counting particles at different depths under a dark-field microscope, as described in detail by Rinberg et al. (2005).

were located $\sim 10-20 \mu \mathrm{m}$ from the outer surface, internal to the epidermis, dermis, and circular muscles. Therefore, the He pressure was adjusted for a peak penetration depth of $\sim 20 \mu \mathrm{m}$ (compare Fig. $1 C$ ). Presence of netrin mRNA in cells was assayed by in situ hybridization $48 \mathrm{~h}$ after the shots (Fig. 2) (the hybridization and immunohistochemical staining protocols are described in supplemental material, available at www.jneurosci.org). Because the longitudinal muscle cells were not visible under the low-power microscope, some shots missed the strips of the muscle cells. A shot to the middle of a strip typically resulted in silencing of netrin expression in two to three muscle cells (Fig. $2 B, C)$. Muscle cells lacking expression of netrin usually had two or more particles, but always at least one particle inside. In 

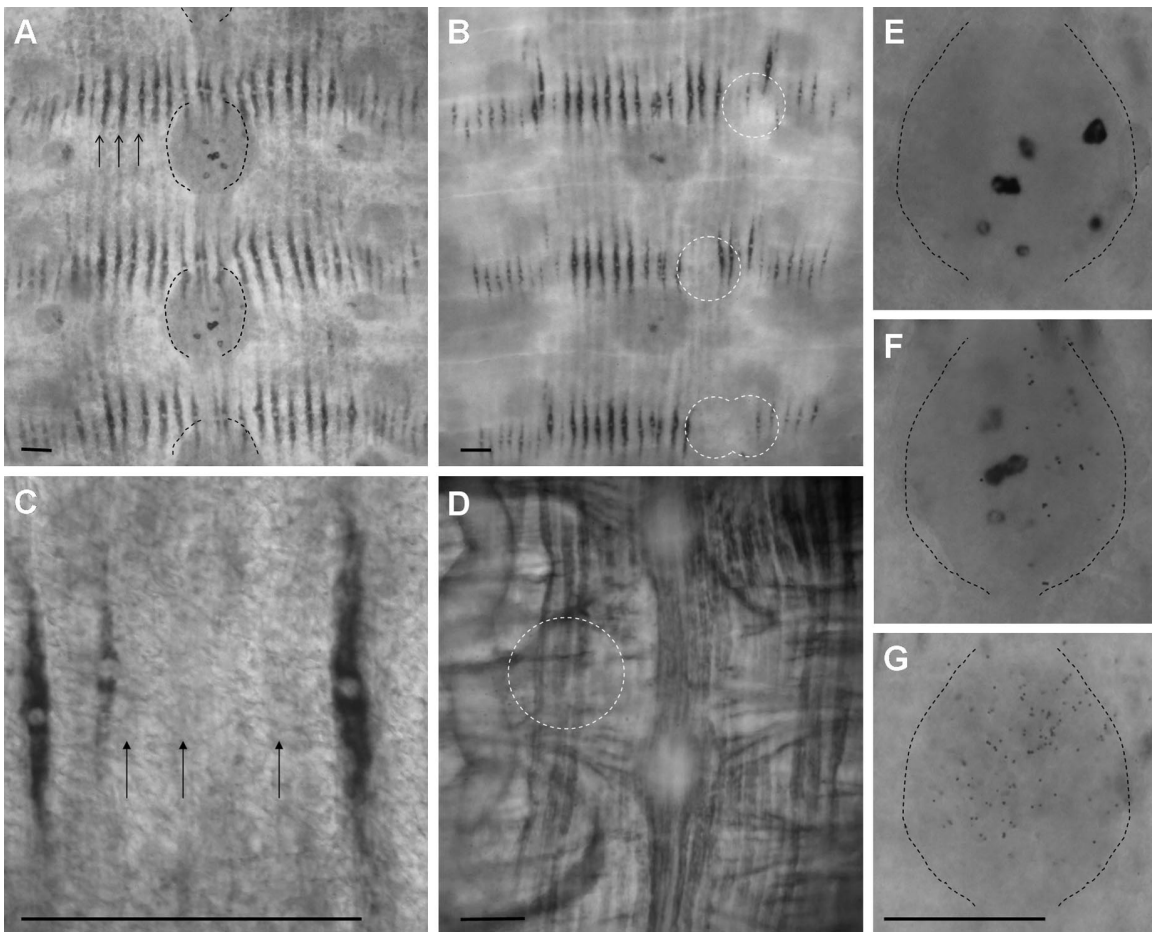

Figure 2. Bright-field micrographs of portions of fixed and processed leech embryos. The embryos in $\boldsymbol{A}-\boldsymbol{C}$ and $\boldsymbol{E}-\boldsymbol{G}$ were stained by in situ hybridization with a netrin probe. $\boldsymbol{A}$, Three midbody segments of an untreated $\mathrm{E} 10$ embryo, showing the normal distribution of netrin mRNA (dark bands) in ventral longitudinal muscle cells (some indicated by arrows) and in neurons in two central ganglia (enclosed by dashed lines). B, An E10 embryo shot with netrin dsRNA-coated particles using the gun. The shot areas are enclosed by white dashed lines. Note the absence of hybridization signals in a number of muscle cells within the encircled areas. C, Close-up image of the area of a shot. Arrows point at cells with netrin mRNA knockdown. D, An embryo stained by hybridization labeling for Act3 constitutively expressed by leech muscle cells. Regular staining in the shot area (white dashed circle) indicates normal expression of actin mRNA in the cells bombarded by netrin dsRNA-coated particles. $\boldsymbol{E}$, An untreated ganglion with netrin mRNA expressed in several neurons (dark spots). $F$, A ganglion after one shot with netrin dsRNA-coated particles, showing visible reduction in netrin mRNA. G, A ganglion that received three shots of the particles, showing complete silencing of netrin expression. The small dark dots in $\boldsymbol{F}$ and $\boldsymbol{G}$ are gold particles. The ganglia in $\boldsymbol{E}-\boldsymbol{G}$ are from the same embryo. Scale bars, $100 \mu \mathrm{m}$.

many instances, particles passed through muscle cells and were observed immediately beyond them, whereas the cells appeared to express netrin normally. These findings indicate that suppression of $n e-$ trin expression does not result from intercellular diffusion of dsRNA or shedding of dsRNA by particles passing through cells and that an amount of dsRNA sufficient to produce detectable netrin knock-down is released only by particles that stop within cells.

Unlike the muscle cells, central ganglia on the ventral side of embryos were easy to see under the microscope, thus permitting accurate and repeatable delivery of the dsRNA-coated particles into an individual ganglion using the laser beam to aim the shot (Fig. 2E-G). The ganglia in the embryonic stages we worked with (E10E12) were located $\sim 50 \mu \mathrm{m}$ within the ventral surface of the body. A shot at the maximal He pressure of 15 psi normally resulted in a visible reduction of netrin expression in the targeted ganglion (Fig.
$2 F)$. Because of substantial thickness of the ganglion $(\sim 50 \mu \mathrm{m})$ and variability of the number of particles in a shot, achieving complete knock-down of netrin expression in a ganglion required multiple shots using different He pressures (Fig. 2G).

To examine the specificity of the RNAi, the expression of a second gene, actin (leech Act3; constitutively expressed in muscles) was tested after shooting the netrin dsRNA-coated particles into the muscle cells. The level of Act3 mRNA appeared to be normal, and no systematic difference was observed when cells with and without particles were compared (Fig. $2 D$ ). In a second test, the carrier particles were coated with dsRNA of a different gene, LAR2 [tested previously in single-cell RNAi assays by microinjection(Baker and Macagno, 2000)] and shot into the muscle cells using the same pressure of He. The cells were assayed for netrin mRNA, and again, no difference between cells with and without particles inside was detected (data not shown). Finally, after bombardment with the netrin dsRNA-coated particles, the muscle cells were immunohistochemically stained with a muscle-specific monoclonal antibody LAZ10-1 (Thorey and Zipser, 1991). Cells in the targeted area stained normally, and no differences were observed between cells with and without particles (data not shown).

\section{Ectopic gene expression}

For the transfection assays, the gold particles were coated with a plasmid containing a leech actin gene, Act1, tagged with the enhanced green fluorescent protein (EGFP) reporter (see supplemental material, available at www.jneurosci.org, for the particle coating protocol). The first assay was performed on neurons on the ventral side of segmental ganglia using the maximal He pressure. This assay had a high rate of success (Fig. $3 A$ ) attributable to the large size of the neuronal nuclei and to the high packing density of neurons in the ganglia. The transfection was highly localized. All neurons expressing EGFPAct1 had at least one particle in their nuclei (Fig. 3A, inset), and epithelial and muscle cells surrounding the targeted ganglion were only rarely transfected. Staining with a nonspecific nucleic marker did not reveal any detectable damage from the particles to neurons in the targeted ganglion and to other cells in the surrounding tissue. The second transfection assay was performed on ventral longitudinal muscle cells using the same DNA plasmid-coated particles (Fig. 3B). The gun was operated at the same conditions as those used in the RNAi assay on the muscle cells. Just as for the neurons, all cells expressing EGFP-Act1 had a particle inside the nucleus (Fig. 3B, inset). The success rate of the muscle cell transfection was substantially lower than that of the RNAi assay because of much smaller volume of the nucleus relative to that of the cell. Nevertheless, expression of EGFPAct1 was observed in multiple muscle cells in different embryos.

\section{Transfection and staining of cultured cells}

We performed localized staining and transfection of mammalian cells (Neuro 2A) in culture using gold particles coated with either a lipophilic fluorescent dye or a DNA plasmid encoding GFP (supplemental Fig. 2, available at www.jneurosci. org as supplemental material). The biolistic delivery of DNA and dye into cultured cells required substantial reduction of the 
particle penetration depth compared with the assays in leech embryos. Therefore, the shots were made at lower He pressures ( $\sim 10-12$ psi) and at larger distances between the gun nozzle and targeted cells $(\sim 10 \mathrm{~mm})$.

\section{Independent delivery of two fluorescent dyes}

To test the possibility of independent delivery of different substances with a single gun, we used particles coated with red and green lipophilic fluorescent dyes (see supplemental material, available at www. jneurosci.org, for particle coating protocols) (Gan et al., 2000), which were loaded into two separate lines of tubing (Fig. $1 B$ ). The shots were made at the maximal $\mathrm{He}$ pressure into segmental ganglia on the ventral side of E10-E12 leech embryos (Fig. 3C). In one type of experiment, after shooting particles coated with one dye, the gun was moved, aimed at an adjacent ganglion, and particles coated with the other dye were shot. The shots generated green fluorescence in one ganglion and red fluorescence in the other ganglion, $\sim 400 \mu \mathrm{m}$ away. Although there were a few dozen particles in each of the two targeted areas, and each particle delivered some amount of dye, there was no visible intermixing of the two colors. In another experiment, the gun was displaced by less than the nozzle diameter between the shots, which generated a pattern of partially overlapping green and red fluorescence (Fig. 3C, inset)

\section{Conclusions}

The pneumatic capillary gun used here delivered gold particles into cells in a small localized volume of a live embryo and in a localized area of a cell culture plate without causing detectable damage to cells in the targeted area. In the embryos, the delivery region had lateral dimensions of $\sim 150 \mu \mathrm{m}$ and extended over $\sim 15 \mu \mathrm{m}$ around the mean penetration depth, which was adjustable between 0 and 50 $\mu \mathrm{m}$ (as measured in fixed tissue). When the particles were coated with netrin dsRNA, they caused clearly visible knockdown of netrin expression that only occurred in cells containing particles (usually, one to two particles per cell). Particles coated with a plasmid encoding EGFPtagged actin induced fluorescence in neuronal cells when they stopped in their nuclei and had little effect on the embryo otherwise. Therefore, the use of the capillary gun gives the technique of biolistic delivery a new capability, to knock-in and knock-down genes in a microscopic re-
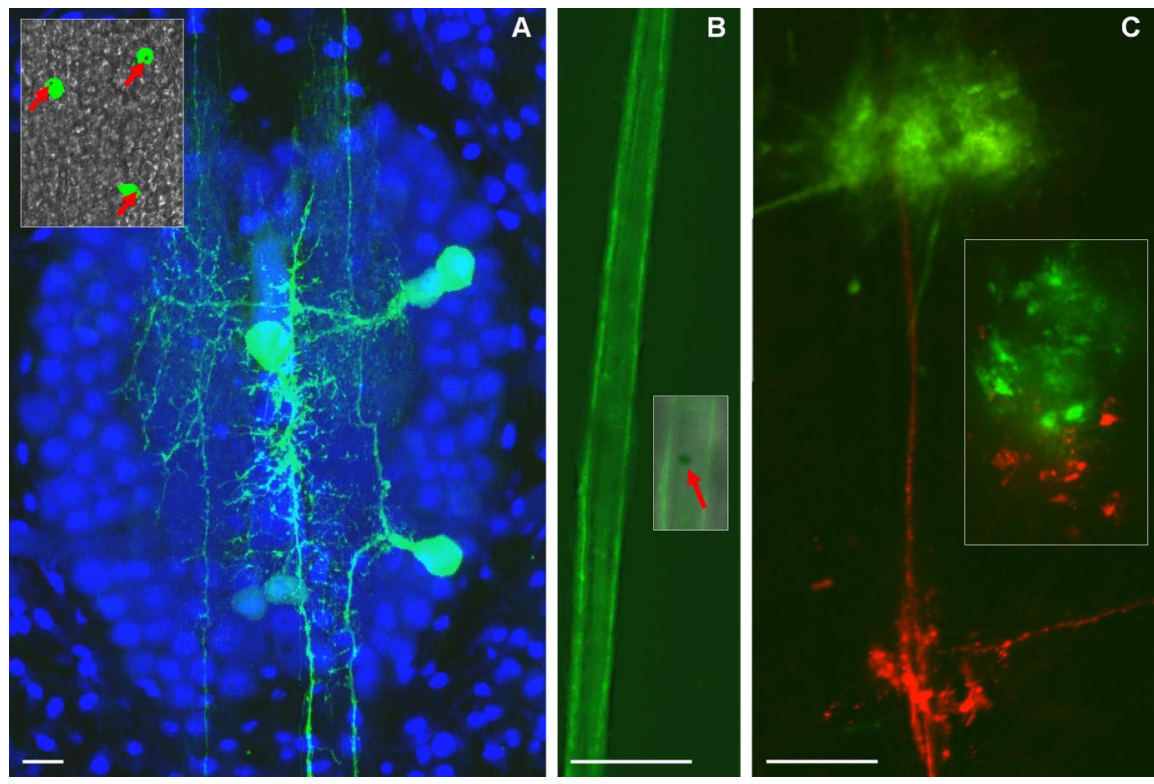

Figure 3. Transfection of central neurons and a longitudinal muscle cell by particles coated with a plasmid encoding EGFP-Act1 and injection of two different lipophilic dyes. (For the details of microscopy, see supplemental material, available at www. jneurosci.org). $\boldsymbol{A}$, Superimposed stack of fluorescence confocal sections of a dorsal region of an embryonic ganglion, $48 \mathrm{~h}$ after a shot. Cell nuclei were counterstained with a nonspecific nucleophilic compound (Hoechst, blue). Expression of EGFP-Act1 is clearly seen in the cell bodies and neurites of three neurons (there were two other expressers in different focal planes). Scale bar, $10 \mu \mathrm{m}$. Inset, Superimposed stack of reflected confocal sections taken in the same planes of the same ganglion; arrows indicate particles. $\boldsymbol{B}$, Longitudinal muscle cell expressing EGFP-Act1, imaged with a confocal microscope $48 \mathrm{~h}$ after a shot. Inset, Magnified image of a fragment of the same cell taken with a transmission filter; one can see a particle in the cell nucleus (red arrow). Scale bar, $10 \mu \mathrm{m}$. C, Fluorescence image showing superposed stacks of confocal sections taken at conditions optimized for detection of green and red fluorescence in a dorsal region of an E10 embryo containing two segmental ganglia. The imaging was performed $2 \mathrm{~h}$ after particles coated with green (DiO) and red (Dil) fluorescent dyes were shot into the upper and lower ganglia, respectively. One can see some diffusion of dyes within cells. Scale bar, $100 \mu \mathrm{m}$. Inset, The same type of confocal image taken in a ganglion of an E10 embryo immediately after particles coated with the red and green dyes were shot into it; the gun was displaced by $\sim 100 \mu \mathrm{m}$ between the shots.

gion of a tissue confined in three dimensions and targeted with high precision, without damage to the tissue.

As a method for RNAi and transfection of cells in a localized region of a tissue, the biolistic delivery of nucleic acids with the gun has several advantages over microcapillary injection and electroporation: it is fast, contact-free, and nondestructive. Unlike localized electroporation (Haas et al., 2002), delivery of substances with the gun has little sensitivity to specific properties of the cells and tissue other than their mechanical strength. The gun targets multiple cells at once, whereas microcapillary injection into multiple neighboring cells would normally be impractical because of the high probability of damage to the cells from the introduction and removal of the capillary tip. The volume of the tissue affected by a single shot can be easily adjusted by varying the diameter of the gun nozzle and the distribution of particle sizes (Rinberg et al., 2005). A unique feature of the gun is the possibility of independent delivery of different substances, with no unwanted intermixing between them and a minimal time required to inject an additional substance.

The specific RNAi-mediated silencing of the expression of the axon guidance factor netrin during embryonic development that is achieved with the gun allows noninvasive microscopic-level control of axonal growth. Because the localized netrin silencing assay is fast and nondestructive, it could be applied at multiple spots of an embryo, allowing a predesigned pattern of innervation cues to be inscribed in an embryo. Furthermore, by using particles with different coatings stored in separate reservoirs and independently injected into the He flow, different sets of dsRNA and plasmid DNA can be delivered to specified regions of a tissue, leading to expression or inhibition of different combinations of genes. If programmable positioning and motion of the gun along with better control of particle injection into the He flow are implemented, we expect that concurrent manipulation of expression of multiple genes according to a predesigned spatial pattern can be achieved using the gun. 


\section{References}

Aisemberg GO, Gershon TR, Macagno ER (1997) New electrical properties of neurons induced by a homeoprotein. J Neurobiol 33:11-17.

Baker MW, Macagno ER (2000) RNAi of the receptor tyrosine phosphatase HmLAR2 in a single cell of an intact leech embryo leads to growth-cone collapse. Curr Biol 10:1071-1074.

Gan WB, Grutzendler J, Wong WT, Wong ROL, Lichtman JW (2000) Multicolor "DiOlistic" labeling of the nervous system using lipophilic dye combinations. Neuron 27:219-225.

Haas K, Jensen K, Sin WC, Foa L, Cline HT (2002) Targeted electroporation in Xenopus tadpoles in vivo-from single cells to the entire brain. Differentiation 70:148-154.

Hon H, Rucker EB, Hennighausen L, Jacob J (2004) bcl-X-L is critical for dendritic cell survival in vivo. J Immunol 173:4425-4432.

Kim TW, Lee JH, He LM, Boyd DAK, Hardwick JM, Hung CF, Wu TC (2005) Modification of professional antigen-presenting cells with small interfering RNA in vivo to enhance cancer vaccine potency. Cancer Res 65:309-316.

Klein TM, Wolf ED, Wu R, Sanford JC (1987) High-velocity microprojectiles for delivering nucleic-acids into living cells. Nature 327:70-73.

Mehier-Humbert S, Guy RH (2005) Physical methods for gene transfer: improving the kinetics of gene delivery into cells. Adv Drug Deliv Rev 57:733-753.

Rinberg D, Simonnet C, Groisman A (2005) Pneumatic capillary gun for ballistic delivery of microparticles. Appl Phys Lett 87:014103.

Thorey IS, Zipser B (1991) The segmentation of the leech nervous system is prefigured by myogenic cells at the embryonic midline expressing a muscle-specific matrix protein. J Neurosci 11:1786-1799.

Wang WZ, Emes RD, Christoffers K, Verrall J, Blackshaw SE (2005) Hirudo medicinalis: a platform for investigating genes in neural repair. Cell Mol Neurobiol 25:427-440. 